HEINZELMANN, Martin, Livrets, collections et textes. Études sur la tradition hagiographique latine

\title{
Damien Kempf
}

\section{OpenEdition}

\section{Journals}

Édition électronique

URL : http://journals.openedition.org/ifha/557

DOI : $10.4000 /$ ifha. 557

ISSN : 2198-8943

Éditeur

IFRA - Institut franco-allemand (sciences historiques et sociales)

Référence électronique

Damien Kempf, « HEINZELMANN, Martin, Livrets, collections et textes. Études sur la tradition

hagiographique latine », Revue de l'IFHA [En ligne], Date de recension, mis en ligne le 01 janvier 2007, consulté le 22 septembre 2020. URL : http://journals.openedition.org/ifha/557 ; DOI : https://doi.org/ 10.4000/ifha.557

Ce document a été généré automatiquement le 22 septembre 2020.

(C)IFHA 


\title{
HEINZELMANN, Martin, Livrets, collections et textes. Études sur la tradition hagiographique latine
}

\author{
Damien Kempf
}

1 Voici la dernière livraison des SHG (« Sources hagiographiques de la Gaule »), acronyme sous lequel est maintenant connu le projet de recherche qui a été conjointement dirigé par François Dolbeau, Martin Heinzelmann et Joseph-Claude Poulain, depuis maintenant une vingtaine d'années. Ce recueil bilingue, franco-allemand, rassemble cinq contributions plutôt hétérogènes, qui ont toutes cependant pour point commun, comme le veut la méthode prônée et suivie par les concepteurs du projet, de considérer le manuscrit, et non le « texte », comme support d'étude.

2 L'article central de ce recueil, de par sa longueur mais aussi par l'ampleur de sa réflexion, aborde un thème primordial pour la recherche en hagiographie, qui n'a pourtant jamais fait l'objet d'une étude détaillée jusqu'à présent. Il s'agit de la question du livret hagiographique (libellus). Le livre est le mode premier, si l'on peut dire, d'existence d'une œuvre hagiographique, avant qu'elle ne trouve place dans un recueil. Il est raisonnable de penser, comme J.-C. POULIN, nous y invite, que « le premier exemplaire d'une œuvre hagiographique fut un livret, copié par son auteur ou mis au net sous sa supervision. » (p. 17). En analysant un échantillon de quelques livrets antérieurs au XIIe s., J.-C.P. entend aborder trois angles d'analyse principaux : d'abord, la nature matérielle du livret ; ensuite, le contenu du projet éditorial, et son évolution au cours de sa transmission ; enfin, le dernier point abordé concerne la réception de ces livrets : pour quel(s) public(s) étaient-ils écrits ? Pour qui et pourquoi ces livrets étaient-ils produits?

3 Tâchons ici de résumer les conclusions principales dégagées par l'auteur, qui définit le livret par la présence simultanée de trois éléments clés : un livre de format modeste, au contenu homogène, qui se limite la plupart du temps, mais pas exclusivement, à un saint unique, et qui est destiné à circuler de façon indépendante. Cette " entité bibliographique autonome ", qui circulait souvent pliée, incluait essentiellement des 
pièces narratives, Vies et Passions, mais elles étaient souvent accompagnées de pièces complémentaires tels que des hymnes ou des sermons. Enfin, ces livrets sont majoritairement consacrés aux saints médiévaux, et leur production est souvent (mais pas nécessairement) liée au lancement ou à la promotion d'un culte local ou régional. Leur caractère fondamentalement maniable et fonctionnel leur permettait d'être des instruments de communication très efficaces : le livret n'était pas produit pour être thésaurisé, mais bien pour circuler. Lointain ancêtre de nos livres de poche, c'était un livre fait pour être lu, non pour être admiré.

4 La question de l'usage des textes hagiographiques est au centre de l'article de M. DIESENBERGER, qui s'intéresse à une collection de textes hagiographiques produite en Bavière, la " collection bavaroise ", vers 800 . L'auteur constate que les trente-cinq textes qui forment ce recueil proviennent de différentes collections, mais que leur sélection et leur reprise répondaient à des choix idéologiques et littéraires assez précis. En effet, ces textes ne furent pas simplement compilés, mais le plus souvent réécrits, en conformité avec les idéaux de réforme promus par les Carolingiens.

5 Les trois autres contributions de ce volume s'ordonnent autour de l'étude de textes et de dossiers hagiographiques spécifiques. F. DOLBEAU s'intéresse ainsi à une hymne composée en l'honneur de saint Vulfran de Fontenelle au tout début du VIIIe s. Ce texte, dont le style hermétique combine des mots hébraïques, grecs et latins, forme un ensemble pour le moins étrange, dont l'édition et le commentaire savamment philologique de F.D. permettent d'apprécier la singularité. Il est plus spécifiquement question de contexte et de causa scribendi, dans l'article de J. LE MAHO, qui propose une nouvelle datation (950/ 960 plutôt que vers 860) de deux vitae, celles de saint Aycadre et de saint Hugues de Jumièges, composées, selon lui, par l'abbaye de Jumièges, afin de célébrer la supériorité de l'ordre des moines, dans le cadre de la renaissance monastique du Xe s. La médiéviste de Göttingen H. RÖCKELEIN clôt ce recueil avec une étude sur un phénomène très particulier et fascinant, celui du dédoublement de saint. À travers l'exemple de Just de Beauvais et en s'appuyant à la fois sur des textes et des images, elle montre comment un saint (Just de Beauvais) pouvait donner naissance à un autre (Justin d'Auxerre), en formant une tradition hagiographique complètement différente. Ce dernier cas d'étude illustre à merveille une des caractéristiques fondamentales de l'hagiographie que la "méthode SHG » s'emploie à souligner, à savoir l'extrême malléabilité des textes et, par conséquent, la nécessité d'analyser ces textes dans leur transmission manuscrite, afin de cerner les conditions de production et d'exploitation d'une parole qui est rarement reproduite mot pour mot, mais au contraire réécrite, réinscrite, en compagnie d'autres textes, générant ainsi de nouveaux systèmes intertextuels.

Damien KEMPF (Bristol University) 